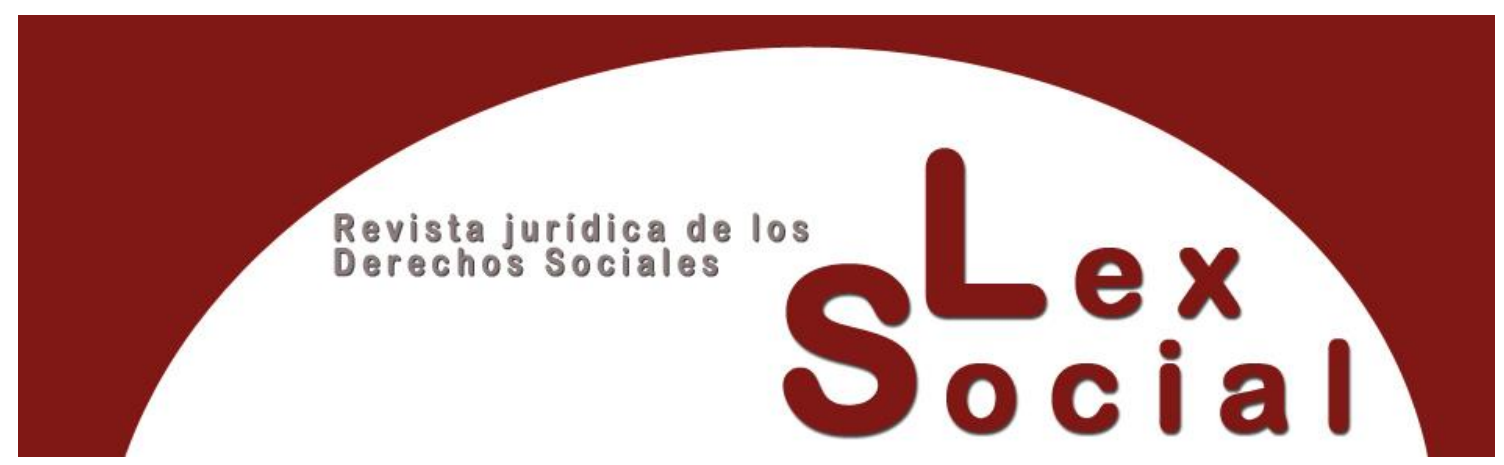

\title{
RECENSIÓN
}

\section{García González, Guillermo, El síndrome del trabajador quemado (o burnout): dimensión jurídica laboral, preventiva y de seguridad social, Cizur Menor, Aranzadi, 2021}

\author{
Dra. AMANDA MORENO SOLANA \\ Profesora de Derecho del Trabajo y Seguridad Social \\ Universidad Carlos III \\ https://orcid.org/0000-0003-2734-6135
}

Cómo citar este trabajo: Moreno Solana, A. (2022). García González, Guillermo, El síndrome del trabajador quemado (o burnout): dimensión jurídica laboral, preventiva y de seguridad social, Cizur Menor, Aranzadi, 2021. Lex Social, Revista De Derechos Sociales, 12 (1), pp. 605-607. https://doi.org/10.46661/lexsocial.6448

El Profesor Guillermo García González, autor de la obra que tengo el gran honor de reseñar, analiza de manera brillante en la monografía "El síndrome del trabajador quemado (o burnout): dimensión jurídica laboral, preventiva y de seguridad social" uno de los riesgos psicosociales más relevantes de nuestro modelo actual de relaciones laborales, cuyas consecuencias sobre las organizaciones, las empresas, el ambiente de trabajo y sobre la salud de los empleados son más que evidentes.

La obra examina de forma detenida, exhaustiva y rigurosa el burnout o síndrome de quemarse en el trabajo. El contexto en el que el estudio se publica no puede ser más oportuno. La creciente digitalización de las relaciones laborales, la consolidación de la denominada "sociedad de la queja" y el contexto pandémico que estamos viviendo, presentan al burnout como una de las manifestaciones de los riesgos psicosociales que están llamadas a tener mayor protagonismo en un futuro inmediato. La oportunidad del estudio se ve reforzada por el reconocimiento oficial que la OMS realizó del burnout

\section{(cc) BY-NC-SA}


como una problemática o fenómeno asociado al trabajo, en la revisión decimoprimera de la CIE, vigente desde el año 2022.

Las propias palabras del autor anticipan el propósito de su estudio: llenar el vacío existente en el iuslaboralismo en relación con el síndrome de quemarse en el trabajo; propósito que parece pertinente y acertado, teniendo en cuenta la escasa atención normativa, doctrinal y jurisprudencial que el burnout ha merecido en nuestro modelo jurídico. La relativa irrelevancia jurídica del burnout contrasta con su creciente importancia social, lo que justifica sobradamente una obra como la que es objeto de comentario.

El estudio de estructura bajo tres dimensiones íntimamente relacionadas: la preventiva, la de seguridad social y la laboral stricto sensu. Cada una de ellas es objeto de un tratamiento diferenciado, que se identifica claramente en el estudio a través de sus diferentes capítulos. Con independencia de ello, la obra interrelaciona las distintas dimensiones a lo largo de todo su contenido, proporcionando una visión global de un fenómeno tan complejo y con tantas aristas como el síndrome de estar quemado.

La obra se articula en seis capítulos que se ordenan de forma lógica y coherente, permitiendo al lector aproximarse de forma sistemática y progresiva al burnout.

El primer capítulo constituye una magnifica introducción que sintetiza perfectamente los elementos configuradores del burnout. Entre otros extremos, se examina la caracterización del síndrome como proceso, la incidencia que en el burnout tienen los antecedentes organizacionales y las variables moduladoras personales, las consecuencias que se derivan del síndrome, y su especial incidencia en determinadas profesiones de carácter asistencial.

Los dos siguientes capítulos se acercan al burnout desde una óptica netamente preventiva. Para ello, el autor se adentra en el exiguo marco jurídico positivo que los riesgos psicosociales tienen en nuestro modelo normativo. La relevancia que esta perspectiva preventiva tiene en relación con el síndrome de estar quemado resulta indudable, pues la prevención de riesgos laborales constituye la vía fundamental a través de la cual el burnout ha logrado insertarse en nuestro ordenamiento jurídico.

Los capítulos dedicados a la dimensión preventiva del burnout (capítulos 2 y 3) estructuran perfectamente sus contenidos con base en dos ejes fundamentales en la prevención de riesgos laborales: la evaluación y la intervención. Partiendo de esta ordenación, el primero de los capítulos referidos profundiza en la evaluación de riesgos psicosociales aplicada al burnout. Lejos de visiones generalistas, el autor se dirige específicamente al análisis de los distintos instrumentos evaluativos singularmente orientados hacia el síndrome. El examen que el autor realiza de la evaluación de riesgos en relación con el burnout sintetiza de forma acertada la naturaleza técnico-jurídica que caracteriza al instrumento evaluativo, y acentúa el fundamental papel que la evaluación de riesgos desempeña en relación con los riesgos psicosociales. Especial mención merecen los apartados que el autor dedica en este capítulo a la evaluación del burnout en 
colectivos especialmente expuestos al síndrome, y que se ligan al sector sanitario y educativo.

Examinada la evaluación del burnout, el tercer capítulo estructura y sistematiza las medidas preventivas frente al síndrome. Acoge el autor la clásica distinción técnicopreventiva entre niveles de prevención primario, secundario y terciario. Partiendo de esta óptica, en cada nivel de intervención se señalan las medidas preventivas a implementar por las organizaciones, ligando dichas medidas con las obligaciones preventivas que se derivan de nuestro derecho de la prevención de riesgos laborales. Se desarrollan en este capítulo aspectos tan esenciales como la formación preventiva, la vigilancia de la salud o los trabajadores especialmente sensibles en su proyección al síndrome de estar quemado.

Los siguientes capítulos (4 y 5) profundizan en las consecuencias que el síndrome de quemarse en el trabajo tiene en materia de seguridad social. Es en el ámbito de la protección social en el que el burnout ha gozado de mayor protagonismo jurídico, principalmente a través de las resoluciones de jueces y tribunales en materia de incapacidades ligadas al síndrome. El burnout ha generado en este punto notables controversias jurisprudenciales que se ligan a dos aspectos esenciales: la consideración del síndrome como accidente de trabajo y el grado de incapacitación que el mismo genera.

El primer aspecto apuntado, la consideración del síndrome de quemarse en el trabajo como accidente laboral, es analizada de forma exhaustiva en el capítulo cuarto. Singular referencia merece en este capítulo el análisis que el autor realiza sobre la calificación del burnout como accidente de trabajo por la vía del art. 156.2 e) LGSS y el controvertido concepto de causa exclusiva de la patología. Complementando la dimensión prestacional, el capítulo 5 de la monografía aborda el grado de incapacidad con la que el burnout se asocia. Para esta tarea, el autor recopila, sistematiza y analiza las resoluciones judiciales que, en relación con este punto, se han generado en nuestro ordenamiento jurídico, permitiéndole esta labor obtener relevantes conclusiones sobre el grado de incapacitación asociado al burnout en nuestro sistema de seguridad social.

Por último, el capítulo 6 de la monografía se dedica a examinar las responsabilidades empresariales derivadas del burnout. La estrecha vinculación del síndrome con incumplimientos preventivos empresariales, genera que se despliegue el complejo sistema de responsabilidades que, directa o indirectamente, se asocian a los incumplimientos de las obligaciones preventivas. Entre otros aspectos, destaca el análisis que se realiza sobre la figura del recargo de prestaciones en supuestos de burnout y sobre la posible extinción causal del contrato de trabajo por parte del trabajador quemado.

Se trata, sin lugar a dudas, de un libro que no puedes dejar de leer y/o consultar si te dedicas a la prevención de riesgos laborales, o simplemente si te interesa el estudio de los riesgos psicosociales, porque ofrece un análisis sencillo, pero muy detallado y riguroso, de las diferentes perspectivas del complejo síndrome del trabajador quemado. 